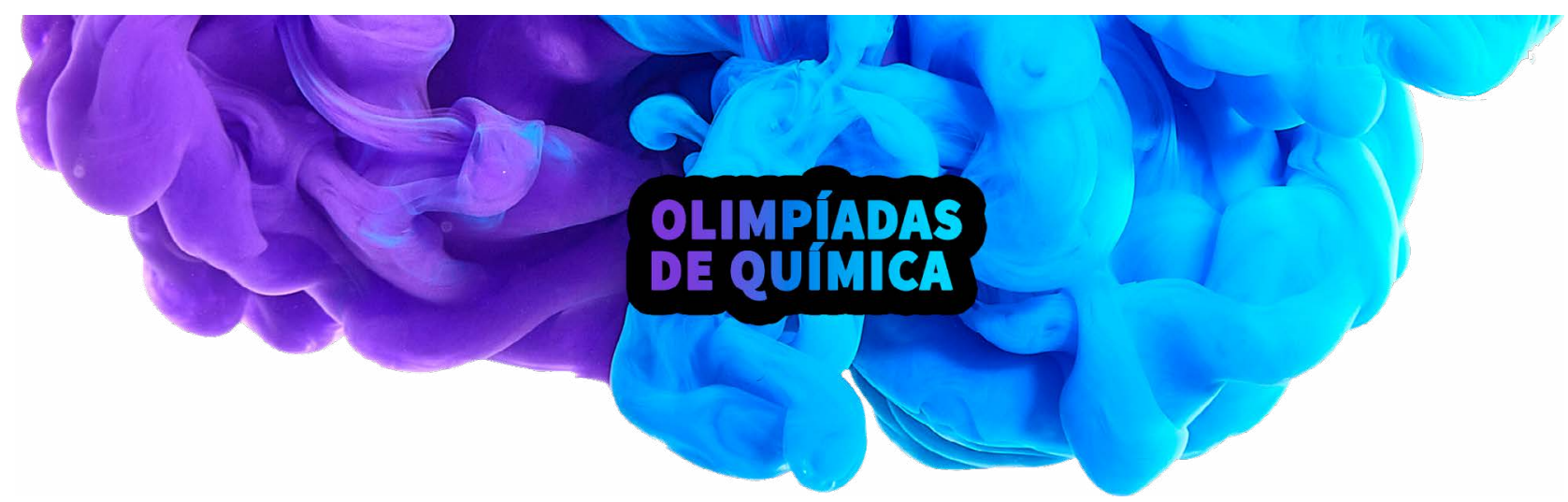

\title{
Olimpíadas de Química 2020
}

A edição de 2020 das Olimpíadas de Química da Sociedade Portuguesa de Química decorreu em plena crise pandémica de COVID-19 e, consequentemente, com um forte impacto logístico na sua realização. As semifinais, que decorrem normalmente entre março e abril, só decorreram na segunda quinzena de julho e as finais, habitualmente realizadas no mês de maio, foram adiadas para 7 de novembro (Mais) e 19 de dezembro (Júnior). A organização, que habitualmente se centraliza nas instituições de ensino superior, foi direcionada para regime online.

\section{As semifinais}

Nas "Olimpíadas de Química Júnior" os alunos participaram a partir de casa através da plataforma espaço elearning-projetos da Universidade de Aveiro, realizando a prova nos seus computadores. Para tal, utilizaram a aplicação Safe Exam Browser e foram acompanhados pelos organizadores das instituições via aplicação Zoom que os alunos abriram através do telemóvel. A prova foi realizada no dia 17 de julho de 2020, mas todos os alunos tiveram a possibilidade de aprender a usar o sistema com uma prova de funcionalidade. 0 mesmo sistema foi usado para a semifinal das "Olimpíadas de Química Mais", com a particularidade de os alunos se encontrarem nas suas escolas e a prova ser realizada no dia 24 de julho de 2020. A execução com sucesso de todo este sistema de realização de provas foi possível com o esforço dos docentes da Universidade de Aveiro, que

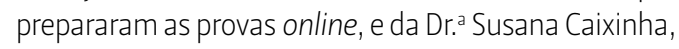
responsável pela plataforma espaço elearning-projetos da Universidade de Aveiro.

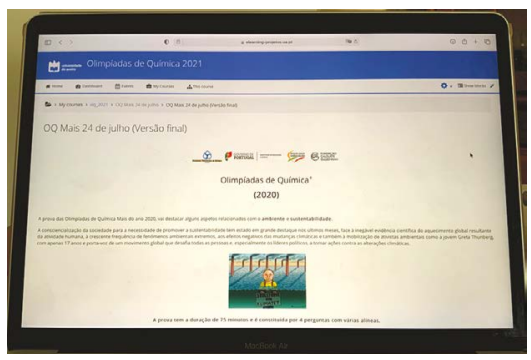

Imagem da página inicial da prova das semifinais das Olimpíadas de Química Mais.

\section{Olimpíadas de Química Júnior - Final}

No dia 19 de dezembro de 2020 decorreu a final das Olimpíadas de Química Júnior, este ano realizada via Zoom a partir do Departamento de Química da Universidade de Coimbra. Apesar das limitações causadas pela pandemia de COVID-19 que obrigou a que as provas não se realizassem presencialmente, a competição gerou, uma vez mais, um grande entusiasmo junto de alunos e professores do ensino básico, tendo sido possível reunir todas as equipas vencedoras das semifinais a nível nacional.

O primeiro lugar (medalha de Ouro) foi conquistado pela equipa "Covalente" (alunos Eleazar Ramos Pereira e João Pedro de Freitas Alexandre, Professor Adelino dos Santos Veríssimo Afonso) da Escola Básica dos 2. ${ }^{\circ}$ e 3. ${ }^{\circ}$ Ciclos Eng. ${ }^{\circ}$ Duarte Pacheco, Loulé). 0 segundo lugar (medalha de Prata) foi ganho pela equipa "Os Estrôncios" (alunos Inês Teixeira Francisco e Afonso Casimiro de Oliveira, Professora Lúcia Pinto), da Academia Vilar Paraíso, Vila Nova de Gaia. Em terceiro lugar, com a medalha de Bronze, ficou a equipa "Átomos" (alunos Maria Rita de Sousa e Silva, Margarida CarvaIhal Martins e Álvaro Gil Azevedo de Castro, Professora Fátima Ferreira) da Escola Secundária Camilo Castelo Branco, Vila Nova de Famalicão.

A Delegaç̧ão de Coimbra da Sociedade Portuguesa de Química parabeniza todos os vencedores e alunos participantes e agradece o apoio a todos os professores, e também por continuarem a transmitir de forma entusiástica o que é a Química. 


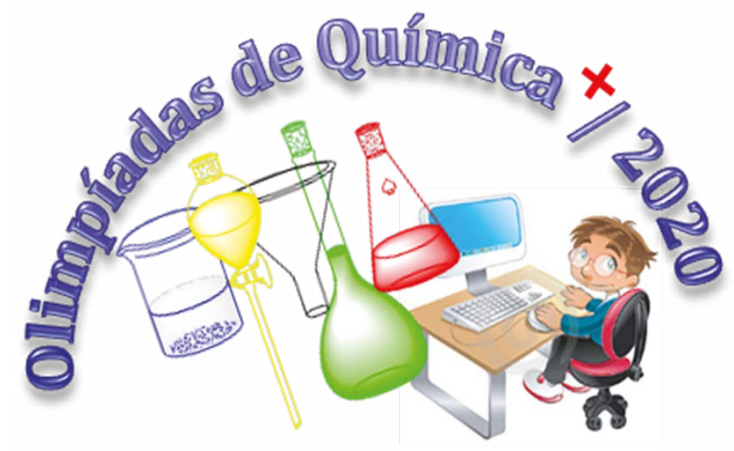

Olimpíadas de Química Mais - Final

A final das Olimpíadas de Química Mais foi realizada a 7 de novembro de 2020 nas Universidades de Aveiro, Algarve e Açores. Este ano, em virtude do estado em que o nosso País se encontra, achou-se por bem evitar longas viagens e convívio entre os participantes. Os alunos das escolas cuja deslocação a Aveiro (local da realização da final) não pôde ser feita no próprio dia fizeram a prova na Universidade mais próxima da sua escola. Por esta razão foram envolvidas três Universidades na realização da final. No entanto, as provas foram corrigidas e classificadas pelo júri de provas de Aveiro.

A medalha de Ouro foi atribuída à aluna Beatriz Crisóstomo Valério Figueiredo, da Escola Secundária
Infanta D. Maria (Coimbra). No segundo lugar, com a medalha de Prata, ficou o aluno João Pedro Bonito Caldeira, também da Escola Secundária Infanta D. Maria (Coimbra). Finalmente, a medalha de Bronze foi entregue ao aluno Pedro Xavier Costa Almeida, da Escola Secundária Alves Martins (Viseu). 0 prémio para melhor escola foi entregue à Escola Secundária Infanta D. Maria (Coimbra).

Os alunos Beatriz Crisóstomo Valério Figueiredo, Daniela Rodrigues Correia, David Moreira Freiria, Gabriel Alberto Mourão Almeida, Gonçalo Pacheco Coelho, Gonçalo Resendes de Sousa, Guilherme Alberto do Couto Gonçalves, João Alexandre Ferreira Almeida, João Pedro Bonito Caldeira, Martim José Batista Lousado e Pedro Xavier Costa Almeida foram selecionados para preparação da participação nas Olimpíadas Internacionais de Química 2020 e Olimpíadas Ibero-Americanas de Química 2020.

A participação portuguesa nas Olimpíadas Internacionais de Química é objeto de outra notícia neste número. Em consequência da pandemia COVID-19 as Olimpíadas Ibero-Americanas de Química 2020, previstas para decorrer no Brasil, foram adiadas para 2021.

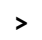

\section{Olimpíadas Internacionais de Química 2020}

As Olimpíadas Internacionais de Química (International Chemistry Olympiad - IChO) decorrem anualmente em local itinerante e são destinadas aos alunos do ensino secundário. Em 2020, a equipa portuguesa, constituída pelos alunos Ana Leitão, Beatriz Figueiredo, João Caldeira e Miguel Borges participou na 52. ${ }^{\circledR}$ edição desta competição, organizada pelo Conselho de Investigacção Científico e Tecnológico da Turquia e pelo Ministério Turco da Indústria e Tecnologia. Esta foi uma competição marcada pelas limitações impostas pela pandemia da COVID-19, consistindo apenas de uma prova teórica realizada remotamente. A equipa portuguesa foi preparada ao longo do ano letivo 2019/2020 através de plataformas de videoconferência e com o apoio do Departamento de Química da Universidade de Aveiro.

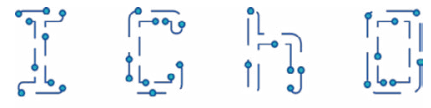

\section{$52^{\text {nd }}$ IChO 2020 \\ International Chemistry Olympiad \\ Istanbul, Turkey}

Apesar da clara desvantagem da ausência de uma prova prática, onde os nossos alunos frequentemente se destacam, obtivemos uma participação positiva no panorama geral. Os alunos realçaram a possibilidade de aprender bastantes conceitos novos e despertar o interesse pela Química. Toda a logística envolvida nesta participação remota, desde discussão de provas com o Conselho Científico, impressão das provas, realização da prova, classificação e discussão de notas decorreu na Universidade de Aveiro, sob a coordenação dos mentores Dr. João Pimenta e Dr. Vasco Batista.

\section{Bruno Machado}

brunofm@fe.up.pt 